\title{
Pregnancy rates and outcomes in women with and without MS in the United States
}

\author{
Maria K. Houtchens, MD, Natalie C. Edwards, MSc, Gary Schneider, ScD, Kevin Stern, BA, \\ and Amy L. Phillips, PharmD
}

Neurology ${ }^{\circledR}$ 2018;91:e1559-e1569. doi:10.1212/WNL.0000000000006384

\author{
Correspondence \\ Dr. Houtchens \\ mhoutchens@ \\ bwh.harvard.edu
}

\section{RELATED ARTICLE}

\section{Editorial}

Pregnancy in multiple sclerosis: Data from an administrative claims database

Page 771

MORE ONLINE

- CME Course

NPub.org/cmelist

\section{Results}

From 2006 to 2014, the adjusted proportion of women with MS and pregnancy increased from $7.91 \%$ to $9.47 \%$; the adjusted proportion without MS and with pregnancy decreased from $8.83 \%$ to $7.75 \%$. The difference in linear trend $(0.17 \%$ increase and $0.15 \%$ decrease in perannum pregnancy rates $)$ was significant $(t$ statistic $=7.8 ; p<0.0001)$. After matching $(\mathrm{n}=2,115$ per group), a higher proportion of women with MS than without had claims for premature labor (31.4\% vs $27.4 \%$; $p=0.005)$, infection ( $13.3 \%$ vs $10.9 \% ; p=0.016)$, cardiovascular disease (3.0\% vs $1.9 \% ; p=0.028)$, anemia/acquired coagulation disorders ( $2.5 \%$ vs $1.3 \% ; p=0.007)$, neurologic complications ( $1.6 \%$ vs $0.6 \% ; p=0.005)$, sexually transmitted diseases $(0.4 \%$ vs $0.1 \% ; p=0.045)$, acquired fetal damage ( $27.8 \%$ vs $23.5 \% ; p=0.002)$, and congenital fetal malformations (13.2\% vs $10.3 \% ; p=0.004)$.

\section{Conclusions}

Pregnancy rates in this population of women with MS have been increasing. High rates of claims for several peripartum complications were observed in women with and those without MS. Claims data provide knowledge of interactions patients have with the health care system and are valuable initial exploratory analyses.

From the Partners MS Center (M.K.H.), Brigham and Women's Hospital, Harvard Medical School, Boston; Health Services Consulting Corporation (N.C.E.), Boxborough; formerly with Boston Health Economics, Inc. (G.S.), Waltham; Boston Health Economics (K.S.), Waltham; and EMD Serono, Inc. (A.L.P.), Rockland, MA.

Go to Neurology.org/N for full disclosures. Funding information and disclosures deemed relevant by the authors, if any, are provided at the end of the article.

The Article Processing Charge was funded by EMD Serono, Inc., Rockland, MA (a business of Merck KGaA, Darmstadt, Germany).

This is an open access article distributed under the terms of the Creative Commons Attribution-NonCommercial-NoDerivatives License 4.0 (CC BY-NC-ND), which permits downloading and sharing the work provided it is properly cited. The work cannot be changed in any way or used commercially without permission from the journal. 


\section{Glossary}

$\mathbf{C C I}=$ Charlson Comorbidity Index; DMD = disease-modifying drug; ICD-9-CM = International Classification of Diseases, Ninth Revision, Clinical Modification; MS = multiple sclerosis.

Multiple sclerosis (MS) is 3 times more common in women than in men, ${ }^{1}$ and clinical onset often occurs as women are considering a family. ${ }^{2} \mathrm{MS}$ is more frequently diagnosed in women of childbearing age than in any other group. ${ }^{3}$ More evidence is needed in order to support decision-making and to improve care of women with MS who are of childbearing age. $^{4-7}$

No studies reporting the rates of pregnancy in women with MS were identified in the published literature. Pregnancy outcomes of women with MS have been evaluated in several studies outside the United States ${ }^{8-20}$; however, only 3 US studies have been published. ${ }^{21-23}$ Mueller et al. $(2002)^{21}$ used Washington state-linked birth certificate/hospital discharge records for 198 women with MS and 1,584 women without MS. Pregnancy or delivery complications, low birth weight or preterm infants, or infants with malformations were not more likely in women with MS. Women with MS were, however, twice as likely to be rehospitalized 3 months after delivery compared with women without MS. Kelly et al. (2009) ${ }^{22}$ compared pregnancy outcomes of 10,055 women with MS with the general obstetric population using 2003-2009 Nationwide Inpatient Sample data. MS was associated with mildly increased odds of antenatal hospitalization, intrauterine growth restriction, and cesarean delivery. Fong et al. (2018) $)^{23}$ used 2001-2009 hospital discharge data from California ( 1,185 deliveries in patients with MS out of $4,424,049$ total deliveries) and found that rates of urinary tract infection, cesarean delivery, and induction of labor were slightly increased in patients with MS; however, antepartum and peripartum morbidities were not increased.

The objectives of this study were to use administrative claims data to (1) evaluate the annual prevalence of pregnancy in women with and without MS during the 2006-2014 interval, and (2) compare pregnancy-related complications in women with and without MS.

\section{Methods}

\section{Data source}

This was a retrospective administrative claims database study using data from the IQVIA Real-World Data Adjudicated Claims-US database from January 1, 2006, to June 30, 2015. This database comprises fully adjudicated health plan claims data and enrollment information for individuals in commercial plans, and contains information from health plans and self-insured employer groups throughout the United States for more than 150 million unique enrollees, collected since 2006. This anonymous, patient-centric database includes all medical and pharmacy claims data (costs and descriptive services) for the enrollees. Claims represent payments to providers for services rendered to covered individuals. Data also include patient-level enrollment, which is a record of demographic variables including eligibility status (birth year, sex, US Census region, eligibility by month). The enrollee population in the database is generally representative of the younger than 65 years, commercially insured population in the United States regarding both age and sex. The average length of enrollment is $\geq 39$ months, and more than 30 million patients have 3 or more years of continuous enrollment (medical and pharmacy coverage). Each contributing plan's data undergo rigorous data quality review by IQVIA prior to its addition into the Real-World Data Adjudicated Claims-US database. The database is deidentified and compliant with the Health Insurance Portability and Accountability Act of 1996. As such, no institutional review board approval was required.

\section{Study populations}

\section{Pregnancy rates over time}

Nine cohorts of patients with and without MS were created—one for each year from 2006 to 2014 - to estimate the prevalence of pregnancy over time. Within each respective year, included patients were required to be enrolled for at least 30 days, be female, and be between the ages of 18 and 64 years as of the first day of the year. Patients with MS were also required to have at least one encounter with a diagnosis of MS (ICD-9-CM code: $340 . x x$ ). Those included in the numerator of the pregnancy prevalence calculation (i.e., pregnant women) were required to have at least one encounter with a diagnosis of pregnancy (table e-1, links.lww.com/WNL/ A712) or a pregnancy-related procedure (table e-2) during their respective year.

\section{Pregnancy outcomes}

For the pregnancy outcomes evaluation, patients were initially required to have any eligibility from January 1, 2006, to June 30,2015 , to be female, to have at least one encounter with a diagnosis of pregnancy (table e-1, links.lww.com/WNL/ A712) or a pregnancy-related procedure (table e-2), to be between the ages of 18 and 64 as of the date of the pregnancy diagnosis, and to have a live birth procedure code (table e-3). The focus of this analysis on women with a live birth was to identify a maximally homogeneous sample for comparative purposes.

The date of the live birth procedure was used to estimate the date of conception and the pregnancy periods. ${ }^{13}$ Continuous eligibility for 1 year before estimated conception and 1 year after the live birth with no gaps in coverage were additional 
inclusion criteria. Patients with MS were required to have at least one encounter with a diagnosis of MS (ICD-9-CM code: 340.xx). Only the first pregnancy from an individual woman in the dataset was included in the analysis.

\section{Data analyses}

\section{Pregnancy rates over time}

Annual pregnancy rates (identified via applicable diagnosis or procedure codes), adjusted for age, region, payer, and Charlson Comorbidity Index (CCI) score (a measure of overall comorbidity based on diagnosis codes in administrative data), were estimated separately among women with and without MS via logistic regression (tables 1 and 2 present the full logistic regression models). Estimates were conducted using all women with MS and on a nationally representative $5 \%$ random sample of all women without MS, provided they met the inclusion criteria described above. This random sample was used as a subset of the general database because of the size of the original patient sample (approximately 58 million unique enrollees) and the logistics associated with analyzing data for such a large number of patients. Statistical comparison of the year-over-year pregnancy rates (i.e., slope of best fit line estimated via linear regression) among women with and without MS during the 2006-2014 study interval was conducted.

\section{Pregnancy outcomes}

Propensity score matching ${ }^{24}$ matched patients with MS 1:1 to a nationally representative $5 \%$ random sample from the approximately 58 million women without MS present in the dataset. A priori, based on a literature review, ${ }^{25}$ we included age, payer, region, and year of pregnancy as covariates in the model. In addition, we used regression modeling to determine other comorbidities associated with the outcome of interest. The comorbidities evaluated in the regression modeling were alcohol abuse, anxiety, arthritis, chronic lung disease, depression, diabetes, gastrointestinal disease, hyperlipidemia, hypertension, hypothyroidism, obesity, other female genital tract disorders, ovarian dysfunction, and thyroid disease. Based on regression modeling results, we also included ovarian dysfunction, other female genital tract disorders, obesity, hypothyroidism, and hypertension as covariates.

Demographic characteristics evaluated included age at pregnancy diagnosis, region at pregnancy diagnosis, and payer type during the 1 year prepregnancy. Clinical characteristics

Table 1 Adjusted model for annual pregnancy rates in women without MS (assumptions were an age of 30 years, Midwest region of the United States, a commercial payer, and a CCI score of 0.25)

\begin{tabular}{|c|c|c|c|c|c|c|c|}
\hline \multicolumn{8}{|c|}{ Adjusted MS model (age, region, payer, CCI) } \\
\hline Name & Estimate & SE & OR & Lower Cl & Upper Cl & $z$ Value & $\operatorname{Pr}(>|z|)$ \\
\hline (Intercept) & 0.28 & 0.03 & 1.32 & 1.24 & 1.41 & 8.32 & $<0.0001^{\circ}$ \\
\hline Age & -0.09 & 0 & 0.92 & 0.91 & 0.92 & -129.82 & $<0.0001^{\circ}$ \\
\hline $\mathrm{CCl}$ & -0.03 & 0.01 & 0.97 & 0.95 & 1 & -2.05 & $0.0404^{\circ}$ \\
\hline Cohort: MS 2007 & -0.02 & 0.03 & 0.98 & 0.92 & 1.04 & -0.64 & 0.5209 \\
\hline Cohort: MS 2008 & -0.02 & 0.03 & 0.98 & 0.93 & 1.04 & -0.55 & 0.5822 \\
\hline Cohort: MS 2009 & -0.04 & 0.03 & 0.96 & 0.91 & 1.02 & -1.26 & 0.2077 \\
\hline Cohort: MS 2010 & -0.08 & 0.03 & 0.93 & 0.87 & 0.98 & -2.49 & $0.0128^{\circ}$ \\
\hline Cohort: MS 2011 & -0.12 & 0.03 & 0.89 & 0.83 & 0.94 & -3.93 & $<0.0001^{\circ}$ \\
\hline Cohort: MS 2012 & -0.14 & 0.03 & 0.87 & 0.82 & 0.93 & -4.39 & $<0.0001^{\circ}$ \\
\hline Cohort: MS 2013 & -0.1 & 0.03 & 0.9 & 0.85 & 0.96 & -3.32 & $0.0009^{\circ}$ \\
\hline Cohort: MS 2014 & -0.13 & 0.03 & 0.88 & 0.82 & 0.93 & -4.13 & $<0.0001^{\circ}$ \\
\hline Payer: Medicaid & 0.72 & 0.03 & 2.05 & 1.94 & 2.16 & 26.32 & $<0.0001^{\circ}$ \\
\hline Payer: Medicare & 0.16 & 0.18 & 1.17 & 0.8 & 1.66 & 0.88 & 0.3814 \\
\hline Payer: Other & 0.08 & 0.02 & 1.08 & 1.05 & 1.11 & 5.08 & $<0.0001^{\circ}$ \\
\hline Region: Northeast & -0.03 & 0.02 & 0.97 & 0.94 & 1.01 & -1.49 & 0.1371 \\
\hline Region: South & -0.1 & 0.02 & 0.9 & 0.87 & 0.94 & -5.66 & $<0.0001^{\circ}$ \\
\hline Region: West & 0.06 & 0.02 & 1.06 & 1.01 & 1.1 & 2.43 & $0.0149^{\circ}$ \\
\hline
\end{tabular}

Abbreviations: $\mathrm{CCI}=$ Charlson Comorbidity Index; $\mathrm{Cl}$ = confidence interval; $\mathrm{MS}=$ multiple sclerosis; OR = odds ratio; SE = standard error.

a Statistical significance. 
Table 2 Adjusted model for annual pregnancy rates in women with MS (assumptions were an age of 30 years, Midwest region of the United States, a commercial payer, and a CCI score of 0.25 )

\begin{tabular}{|c|c|c|c|c|c|c|c|}
\hline \multicolumn{8}{|c|}{ Adjusted MS model (age, region, payer, $\mathrm{CCI}$ ) } \\
\hline Name & Estimate & SE & OR & Lower Cl & Upper Cl & $z$ Value & $\operatorname{Pr}(>|z|)$ \\
\hline (Intercept) & 1.38 & 0.05 & 3.96 & 3.56 & 4.39 & 25.76 & $<0.0001^{\mathrm{a}}$ \\
\hline Age & -0.13 & 0 & 0.88 & 0.88 & 0.88 & -120.2 & $<0.0001^{\mathrm{a}}$ \\
\hline CCl & -0.07 & 0.01 & 0.93 & 0.9 & 0.95 & -5.81 & $<0.0001^{\mathrm{a}}$ \\
\hline Cohort: MS 2007 & 0.05 & 0.05 & 1.05 & 0.95 & 1.15 & 0.98 & 0.3291 \\
\hline Cohort: MS 2008 & 0.09 & 0.05 & 1.09 & 1 & 1.19 & 1.87 & 0.0616 \\
\hline Cohort: MS 2009 & 0.12 & 0.05 & 1.13 & 1.03 & 1.24 & 2.7 & $0.007^{a}$ \\
\hline Cohort: MS 2010 & 0.16 & 0.05 & 1.17 & 1.07 & 1.28 & 3.41 & $0.0007^{a}$ \\
\hline Cohort: MS 2011 & 0.16 & 0.05 & 1.17 & 1.07 & 1.28 & 3.49 & $0.0005^{a}$ \\
\hline Cohort: MS 2012 & 0.12 & 0.05 & 1.13 & 1.03 & 1.23 & 2.54 & $0.0112^{a}$ \\
\hline Cohort: MS 2013 & 0.16 & 0.05 & 1.17 & 1.07 & 1.28 & 3.31 & $0.0009^{a}$ \\
\hline Cohort: MS 2014 & 0.18 & 0.05 & 1.2 & 1.1 & 1.32 & 3.91 & $<0.0001^{\mathrm{a}}$ \\
\hline Payer: Medicaid & 0.06 & 0.07 & 1.07 & 0.92 & 1.22 & 0.9 & 0.3703 \\
\hline Payer: Medicare & -0.27 & 0.16 & 0.77 & 0.55 & 1.03 & -1.67 & 0.0945 \\
\hline Payer: Other & 0.04 & 0.02 & 1.04 & 0.99 & 1.08 & 1.66 & 0.0961 \\
\hline Region: Northeast & 0.06 & 0.03 & 1.06 & 1.01 & 1.12 & 2.39 & $0.0168^{a}$ \\
\hline Region: South & -0.2 & 0.03 & 0.82 & 0.78 & 0.86 & -7.71 & $<0.0001^{\mathrm{a}}$ \\
\hline Region: West & -0.07 & 0.04 & 0.93 & 0.87 & 1 & -1.91 & 0.0564 \\
\hline
\end{tabular}

Abbreviations: $\mathrm{CCl}=$ Charlson Comorbidity Index; $\mathrm{Cl}$ = confidence interval; $\mathrm{MS}=$ multiple sclerosis; $\mathrm{OR}$ = odds ratio; $\mathrm{SE}=$ standard error .

${ }^{\text {a }}$ Statistical significance.

evaluated during the 1 year prepregnancy included overall comorbidity as measured by the CCI, and the individual rates of the most common comorbidities in MS (i.e., alcohol abuse, anxiety, arthritis [rheumatoid arthritis or osteoarthritis], chronic lung disease, depression, diabetes [type 1 and type 2], gastrointestinal disease, hyperlipidemia, hypertension, and thyroid disease). These comorbidities were selected as they are among the most common in MS based on the published literature. $^{17}$

We evaluated pregnancy outcomes, which included complications during pregnancy, labor and delivery, and the puerperium period. Clinically relevant ICD-9-CM codes indicating pregnancy complications were selected and categorized (tables e-4 to e-6, links.lww.com/WNL/A712). The broad inclusion of ICD-9-CM codes was intended to encompass all potentially relevant diagnoses to capture any possible differences in outcomes for women with MS vs those without MS.

Sample selection and creation of analytic variables were performed using the Instant Health Data Platform (Boston Health Economics, Inc., Boston, MA). Statistical analyses were undertaken with $\mathrm{R}$, version 3.2.1 ( $\mathrm{R}$ Foundation for
Statistical Computing, Vienna, Austria) and SAS, version 9.4 (SAS Institute Inc., Cary, NC). For descriptive (i.e., unadjusted) analyses, categorical variables were summarized using frequencies and percentages, and continuous variables were summarized using means (with confidence intervals), SDs, and medians (with interquartile ranges). For the analyses of the matched datasets of patients with and those without MS, pairwise $\chi^{2}$ tests evaluated differences between categorical variables, and paired $t$ tests evaluated differences in continuous variables.

\section{Data availability}

The data utilized for this study were obtained through a license agreement with IQVIA.

\section{Results}

\section{Pregnancy rates over time}

\section{Sample selection}

The number of women without MS from the 5\% nationally representative random sample who were included in the annual study cohorts from 2006 to 2014 ranged from 735,974 to $1,144,868$. The number of women with an MS encounter who 
were included in the annual study cohorts from 2006 to 2014 ranged from 36,361 to 58,218 .

\section{Baseline characteristics}

There was little year-to-year variation in age; the mean age of the 9 annual cohorts of women with MS and a pregnancyrelated claim ranged from 29.2 to 29.6 years (table e-7, links. lww.com/WNL/A712). The highest proportion of women without MS and with a pregnancy diagnosis were between the ages of 25 and 29 years (range: $29.9 \%-31.8 \%$ ), lived in the South (range: $27.0 \%-37.6 \%$ ), and had commercial health insurance (range: 89.4\%-93.2\%). The mean age of pregnant women with MS was somewhat greater than that of pregnant women without MS (approximately 32.5 vs 29.3 years), with little year-to-year variation (table e-8). The mean age of women with MS and a pregnancy-related claim ranged from 32.2 to 33.0 years, and the highest proportion of women with MS and a pregnancy diagnosis were between the ages of 30 and 34 (range: $32.8 \%-39.3 \%$ ), lived in the Northeast (range: $30.0 \%-36.9 \%$ ), and had commercial health insurance (range: $95.3 \%-99.0 \%)$.

The mean CCI score of women without MS and a pregnancy diagnosis ranged from 0.14 to 0.16 (table e-9, links.lww. com/WNL/A712). Common comorbidities in this group were gastrointestinal diseases (range: 7.1\%-10.2\%), thyroid disease (range: 6.5\%-8.8\%), hypertension (range: $4.7 \%-5.6 \%$ ), and anxiety (range: $4.4 \%-9.1 \%$ ). The mean CCI score of women with MS and a pregnancy diagnosis ranged from 0.28 to 0.37 (table e-10). Common comorbidities in this group were gastrointestinal diseases (range: $12.3 \%-17.2 \%$ ), thyroid disease (range: $10.8 \%-14.9 \%$ ), hypertension (range: $8.0 \%-11.0 \%$ ), and anxiety (range: $8.0 \%-15.7 \%)$.

\section{Pregnancy rates}

The unadjusted proportion of women without MS who had a pregnancy-related claim decreased from 5.55\% in 2006 to $5.15 \%$ in 2014 (table e-11, links.lww.com/WNL/A712). The unadjusted proportion of women with MS who had a pregnancy-related claim increased from $2.40 \%$ in 2006 to $2.57 \%$ in 2014 (table e-12).

The difference between the 2 groups remained after adjusting for age, region, payer, and CCI score. The adjusted proportion of women without MS who had a pregnancy decreased from $8.83 \%$ in 2006 to $7.75 \%$ in 2014 (figure 1). The adjusted proportion of women with MS who had a pregnancy increased from $7.91 \%$ in 2006 to $9.47 \%$ in 2014 (figure 1). Comparing women with and without MS, the difference in linear trend $(0.17 \%$ increase and $0.15 \%$ decrease in perannum pregnancy rates, respectively) was statistically significant $(t$ statistic $=7.8, p<0.0001)$. The model assumptions were an age of 30 years, Midwest region of the United States, a commercial payer, and CCI score of 0.25 (assumptions approximated the median values). The adjusted models are shown in tables 1 and 2 .
Figure 1 Adjusted proportion of women with and without MS and with a pregnancy, by year

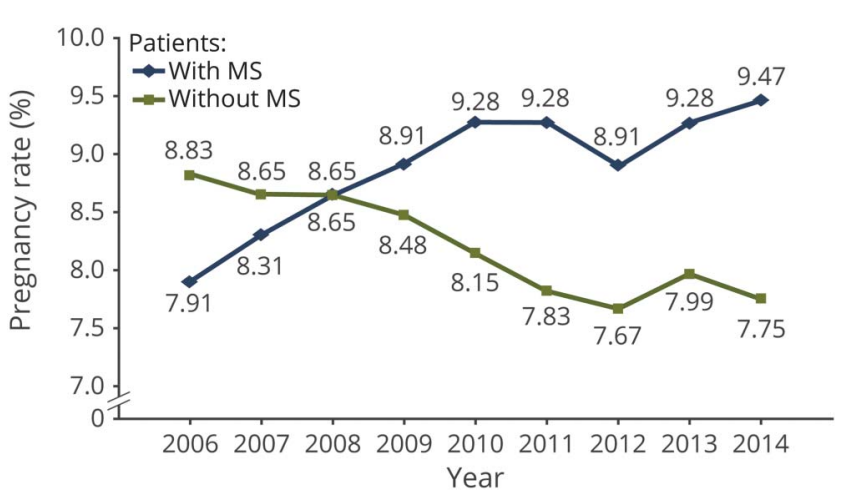

Model assumptions were age $=30$ years, region $=$ Midwest, payer $=$ commercial, and Charlson Comorbidity Index score $=0.25$ (assumptions approximated the median values). MS = multiple sclerosis.

\section{Pregnancy outcomes}

\section{Sample selection}

A total of 5,374,616 patients without a diagnosis of MS and 274,501 patients with a diagnosis of MS were identified from the IQVIA Real-World Data Adjudicated Claims- US database from 2006 to 2015. A total of 39,377 patients without MS and 2,176 patients with MS had a pregnancy diagnosis, were between the ages of 18 and 64 years as of the date of the pregnancy diagnosis, had a live birth procedure code, and had 1-year insurance eligibility before and after the estimated pregnancy period.

\section{Baseline characteristics}

A total of 39,377 women with a live birth without MS and 2,176 women with a live birth with MS met the inclusion criteria. Demographics of women with a live birth without and with MS are presented in table 3. Among women who had a live birth, mean and median ages were higher in those with MS than in those without MS. Most women who had a live birth had commercial health insurance (98.5\% with MS vs $94.7 \%$ without MS). Among women with MS, more were from the Midwest (31.3\%) than any other region, whereas among women without MS, more were from the South (32.1\%). The mean prepregnancy CCI score was statistically significantly higher in women with MS than in women without MS $(p<0.0001)$. Common comorbidities (present in $\geq 10 \%$ of women with MS who had a live birth) were gastrointestinal disease, anxiety, thyroid disease, and depression. The proportion of women with all of the comorbidities except alcohol abuse was statistically significantly higher in women with MS than in women without MS $(p<0.05)$.

After 1:1 matching, 2,115 women without MS and 2,115 women with MS (mean [SD] age 31.31 [4.93] years without MS and 31.38 [4.76] years with MS) were matched. Most had commercial insurance (98.72\%-98.91\%), and the highest 
Table 3 Baseline characteristics of women with a live birth without and with MS

\begin{tabular}{|c|c|c|c|}
\hline Statistic & Patients without MS & Patients with MS & $p$ Value \\
\hline No. & 39,377 & 2,176 & \\
\hline Age, y & & & $<0.0001^{a}$ \\
\hline Mean (SD) & $29.4(5.5)$ & $31.4(4.8)$ & \\
\hline Median (IQR) & $29(26-33)$ & $31(28-35)$ & \\
\hline Age grouping, y, n (\%) & & & $<0.0001^{a}$ \\
\hline $18-24$ & $7,291(18.5)$ & $165(7.6)$ & \\
\hline $25-29$ & $12,634(32.1)$ & $594(27.3)$ & \\
\hline $30-34$ & $12,570(31.9)$ & $857(39.4)$ & \\
\hline $35-39$ & $5,677(14.4)$ & $464(21.3)$ & \\
\hline$\geq 40$ & $1,205(3.1)$ & $96(4.4)$ & \\
\hline Payer, n (\%) & & & $<0.0001^{a}$ \\
\hline Commercial & $37,300(94.7)$ & $2,144(98.5)$ & \\
\hline Medicaid & $2,042(5.2)$ & $28(1.3)$ & \\
\hline Medicare & $35(0.1)$ & $4(0.2)$ & \\
\hline Region, n (\%) & & & $<0.0001^{a}$ \\
\hline Midwest & $11,249(28.6)$ & $681(31.3)$ & \\
\hline Northeast & $8,679(22.0)$ & $611(28.1)$ & \\
\hline South & $12,646(32.1)$ & $653(30.0)$ & \\
\hline West & $5,492(13.9)$ & $173(8.0)$ & \\
\hline Prepregnancy $\mathrm{CCl}$ score & & & $<0.0001^{a}$ \\
\hline Mean (SD) & $0.11(0.41)$ & $0.21(0.60)$ & \\
\hline Median (IQR) & $0(0-0)$ & $0(0-0)$ & \\
\hline \multicolumn{4}{|l|}{ Comorbidities, n (\%) } \\
\hline Alcohol abuse & $156(0.4)$ & $6(0.3)$ & 0.4834 \\
\hline Anxiety & $2,487(6.3)$ & $267(12.3)$ & $<0.0001^{a}$ \\
\hline Arthritis & $434(1.1)$ & $46(2.1)$ & $<0.0001^{a}$ \\
\hline Chronic lung disease & $1,848(4.7)$ & $123(5.7)$ & $0.0457^{\mathrm{a}}$ \\
\hline Depression & $2,195(5.6)$ & $219(10.1)$ & $<0.0001^{a}$ \\
\hline Diabetes & $613(1.6)$ & $57(2.6)$ & $0.0002^{\mathrm{a}}$ \\
\hline Gastrointestinal disease & $3,216(8.2)$ & $286(13.1)$ & $<0.0001^{a}$ \\
\hline Hyperlipidemia & $1,915(4.9)$ & $169(7.8)$ & $<0.0001^{a}$ \\
\hline Hypertension & $1,387(3.5)$ & $122(5.6)$ & $<0.0001^{a}$ \\
\hline Thyroid disease & $2,455(6.2)$ & $235(10.8)$ & $<0.0001^{a}$ \\
\hline
\end{tabular}

Abbreviations: $\mathrm{CCl}=$ Charlson Comorbidity Index; IQR = interquartile range; MS = multiple sclerosis.

${ }^{\text {a }}$ Significant $p$ values $(p<0.05)$.

proportions resided in the Midwest (32.20\%-32.81\%), South (30.88\%-31.02\%), or Northeast $(28.46 \%-28.75 \%)$ regions of the United States (figure e-1 [links.lww.com/WNL/A711] presents propensity score balance for the 2 groups, and table e-13 [links.lww.com/WNL/A712] presents balance statistics for the covariates in each group). 
Pregnancy, labor and delivery, and puerperium complications

Pregnancy complications of matched women with and without a diagnosis of MS who had a live birth are presented in figure 2 . There was a statistically significantly higher proportion of women with a live birth with MS who had a claim for premature labor $(p=0.005)$, infection in pregnancy $(p=$ $0.016)$, maternal cardiovascular disease $(p=0.028)$, anemia or acquired coagulation disorder $(p=0.007)$, neurologic complications in pregnancy $(p=0.005)$, and sexually transmitted diseases in pregnancy $(p=0.045)$ compared with women with a live birth without MS. Women with a live birth without MS had a higher rate of postterm pregnancy $(p<0.001)$ compared with women with a live birth with MS.

Figure 3 presents complications during labor and delivery for matched women with and without a diagnosis of MS who had a live birth. There was a statistically significantly higher proportion of women with a live birth with MS who had a claim for acquired damage to the fetus $(p=0.002)$ and congenital fetal malformations $(p=0.004)$ compared with women with a live birth without MS.

Figure 2 Complications during pregnancy in matched women with and without MS who had a live birth

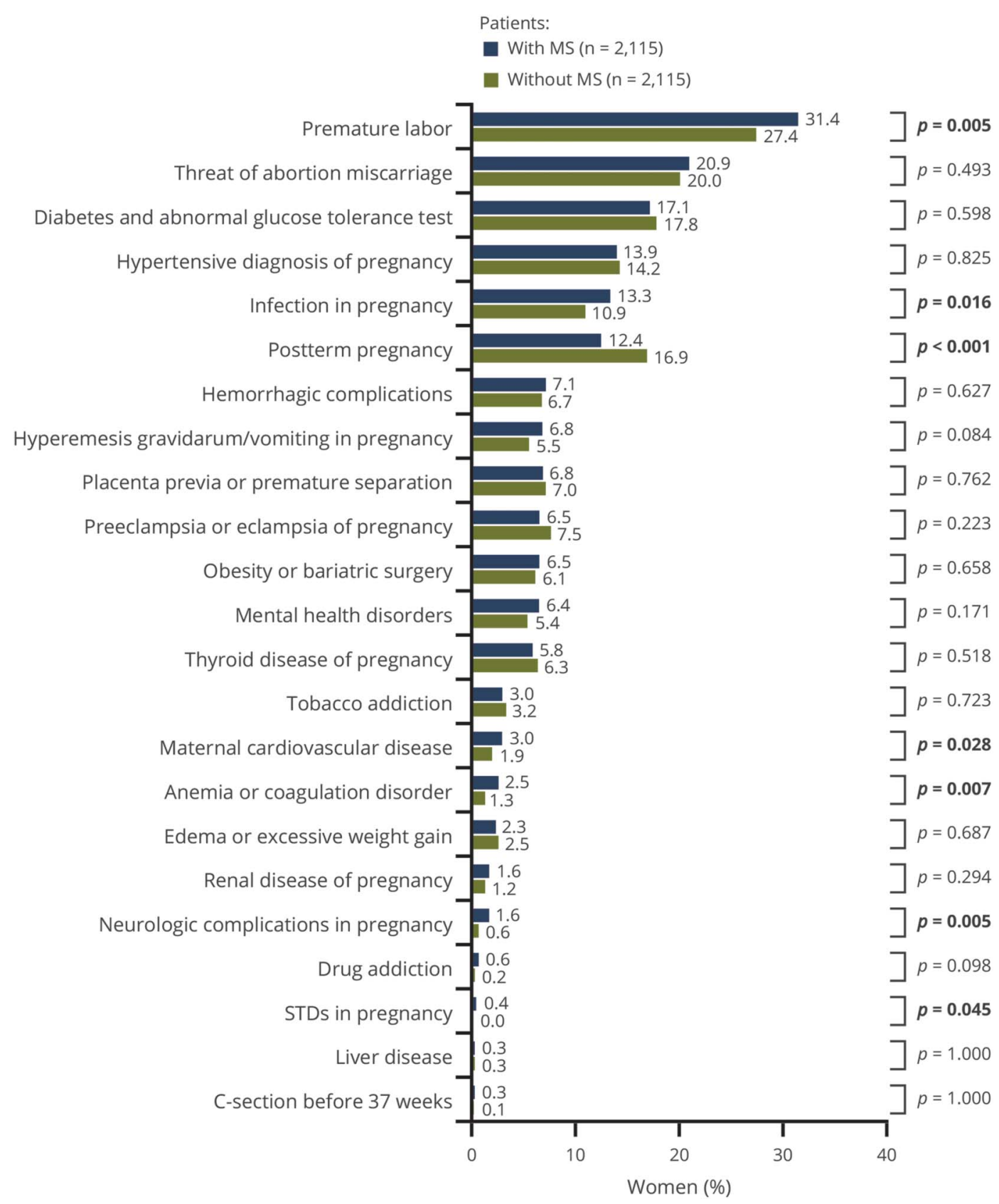

Significant $p$ values $(p<0.05)$ are shown in bold italic text. C-section = cesarean section; MS = multiple sclerosis; STD = sexually transmitted disease. 
Figure 3 Labor and delivery complications in matched women with and without MS and a live birth

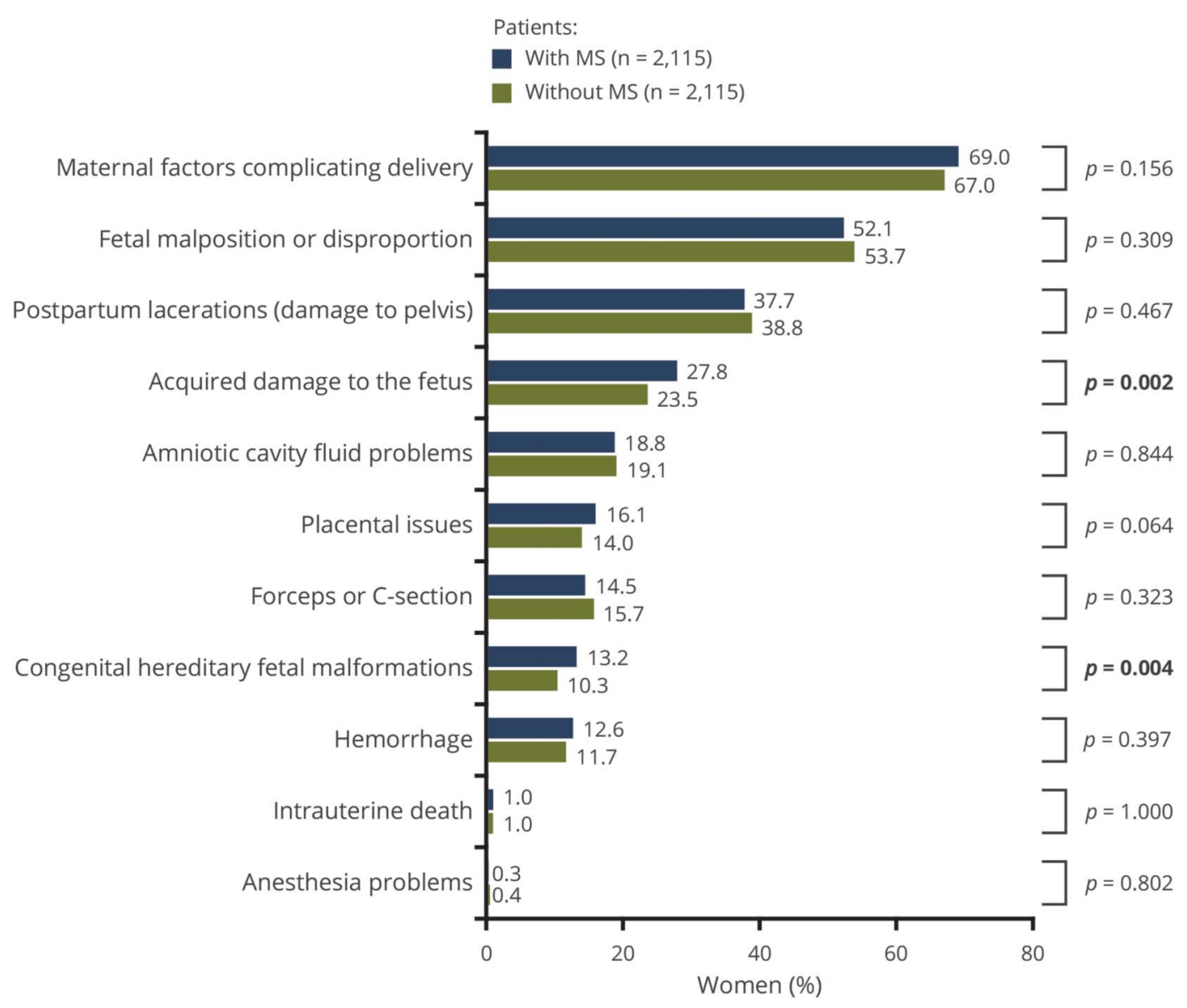

Significant $p$ values $(p<0.05)$ are shown in bold italic text. C-section = cesarean section; MS = multiple sclerosis.

Complications during the puerperium period were not as common as complications during pregnancy and labor and delivery in both patients with and those without MS. The most common complication for both groups was failed, disordered, or suppressed lactation (3.5\% for patients without MS and 3.0\% for patients with MS). There were no significant differences in puerperium complications between the 2 groups (figure 4).

\section{Discussion}

Pregnancy in women with MS can be complex, both from the patient and the provider perspective ${ }^{4}$; yet, few detailed evaluations of specific issues of pregnancy in MS have been reported in North American populations. Approximately three-quarters of patients with MS are women, and clinical onset typically occurs during their childbearing years, between the ages of 20 and 40 years. $^{3}$ It is estimated that between onefifth and one-third of women with MS deliver a child after disease onset, ${ }^{18,20}$ making pregnancy in women with MS relevant to patients, their family members, and health care professionals. ${ }^{19}$ A better understanding of the "real-world" outcomes of women with MS and pregnancy is important for providing quality care to women with MS who are considering a family.

An increase in the prevalence of pregnancy was observed in women with MS from 2006 to 2014, in contrast to a decrease in the prevalence of pregnancy observed in women without MS. The finding of decreased rates of pregnancy in women without MS is consistent with Centers for Disease Control and Prevention data that show steadily declining pregnancy rates for all women in the United States since $1990 .^{26}$ The contrasting increase in pregnancy for women with MS may reflect a change in perceptions and adoption of a positive outlook and improved counseling for patients and providers regarding pregnancy risks in this patient population. Over the last 2 decades, there have been significant efforts on the part of MS neurologists to educate the public and the general neurology community of the reciprocal effects between pregnancy and MS., 3,6

Women with MS tended to be somewhat older than the general population at the time of pregnancy diagnosis. This is consistent with findings in other previously published 


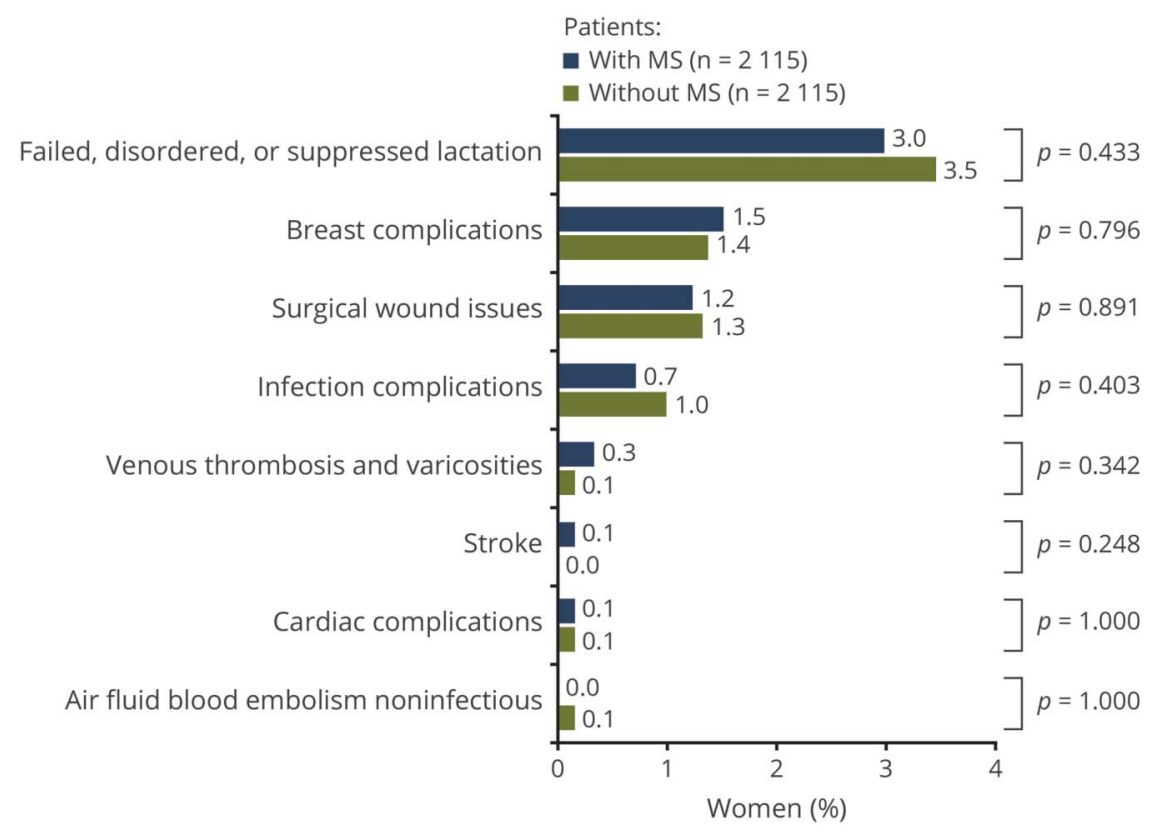

MS = multiple sclerosis

data. ${ }^{8-10,21,23}$ The decision to start or enlarge a family can be complicated by chronic conditions such as MS. Concerns about the health of a child, societal attitudes, unpredictability of neurologic symptoms during or after pregnancy, and issues regarding the appropriate time to discontinue diseasemodifying drugs (DMDs) in order to become pregnant can all delay pregnancy in women with MS. ${ }^{19,27-30}$ A conception delay could be related to the need to stabilize a newly diagnosed patient before conception attempts. ${ }^{4}$ In addition, there is some evidence of a possible decrease in fertility in women with $\mathrm{MS}{ }^{31,32}$ although no final conclusions can be made on this subject.

Both groups of patients had higher rates of labor and delivery complications than generally reported in the literature. ${ }^{33}$ Compared with women without MS and a live birth, women with MS and a live birth in the current study were significantly more likely to have claims for premature labor, infection during pregnancy, acquired damage to the fetus, and congenital hereditary fetal malformations. These data, which are derived from reimbursement information or the payment of bills for health care services and commodities, can improve our knowledge of the interactions that patients with pregnancy and MS have with the health care system, but they should be interpreted with caution. ${ }^{32,34,35}$ There may be biases in coding and billing associated with this specific analysis. For example, there may be increased health care resource utilization in women with MS because of increased vigilance of clinicians caring for these patients. The data do not include Expanded Disability Status Scale score, disease duration, or the numbers or outcomes of prior pregnancies. Other data sources or study designs could provide additional clinical details; however, the findings of the current study suggest important hypotheses for exploration.

The magnitude of the rates of complications also requires further investigation. The high rates of complications may be attributable to the comprehensiveness of the included ICD9-CM codes. Any nonspecific ICD-9-CM codes (unspecified or other) from 9 of the pregnancy and labor and delivery outcome categories were removed to determine whether there was an effect on findings. The differences observed in the absolute rates of complications were small, and there was no statistically significant change in the original findings. More detailed analyses of subsets of the coding lists might provide additional insight into the specific origin of the observed differences. Other important areas of additional research include clinical outcomes that were not included in this dataset, such as the occurrence of spontaneous abortions. This information would likely not be adequately captured in administrative claims data, given that these data are based on the payment information for medical care and services.

A large retrospective cohort study using hospital discharge data from California from 2001 to 2009, which described the prevalence, sociodemographic features, and antenatal/ peripartum outcomes of MS, was published recently. ${ }^{23}$ A total of 1,185 of 4,424,049 deliveries were in women with MS. Similar to findings in the current study, patients with MS in this study were shown to be older, were more likely to have 
private insurance, and were more likely to have preexisting medical conditions such as asthma, chronic hypertension, thyroid disease, or cardiac disease. Urinary tract infection, cesarean delivery, and induction of labor were slightly increased in patients with MS; however, antepartum and peripartum morbidities (gestational diabetes, preeclampsia/ eclampsia, preterm rupture of membranes, fetal growth restriction, oligohydramnios, abruption, placenta previa, operative vaginal delivery, shoulder dystocia, chorioamnionitis, endometritis, or postpartum hemorrhage) were not found to be increased in patients with MS. The differences observed in this study compared with the current findings may be attributable to the different sources of data used. The California study used statewide hospital discharge data reflective of all patients with all types of insurance, whereas our nationally representative sample primarily evaluated patients with commercial insurance. Hospital discharge data reflect resources that were charged for by hospitals, whereas claims data reflect health care resources reimbursed by insurers.

There are some additional limitations of this retrospective claims database analysis. It is possible that patients were given a diagnosis or had a pregnancy prior to the selected index diagnosis. Only the first identified pregnancy was included in the analysis. Furthermore, the date of the live birth procedure was used to estimate the date of conception and the pregnancy periods. ${ }^{9}$ It is possible that there was a misclassification of the prepregnancy period and the following trimesters in some cases; however, it is not expected that this would alter the results fundamentally. Matching factors were determined a priori based on a literature review; however, unknown or unmeasured variables may result in residual confounding. Finally, these administrative claims data are derived mostly from patients with commercial health insurance. These data may not be generalizable to patients who pay for health care out of pocket or for patients who do not have health insurance from their employers.

The knowledge gaps regarding pregnancy and MS are substantial, and many well-designed studies are needed. Existing MS pregnancy registries and adverse event databases are incomplete as data are not collected in a standardized manner. ${ }^{36}$ There is a need for collection of detailed information such as family history, ethnicity, pregnancy history, drug and environmental exposures, and mother's health status with respect to MS and other illnesses. ${ }^{36}$ The Multiple Sclerosis Centre of Excellence on Reproduction and Child Health, an international collaborative multidisciplinary research consortium, was convened in order to address the need for evidence-based, current information regarding childbearing in MS. ${ }^{4}$ Prospective, disease-specific pregnancy registries such as PREG-MS, a US data repository that follows women with MS from pregnancy planning through any stage of pregnancy to 3 years postpartum, collects clinically relevant data that can support pregnancy-related decisionmaking. ${ }^{37}$
Pregnancy rates in women with MS have been increasing over the past 10 years. It is tempting to suggest that recent DMDs have helped more patients with MS achieve disease stability, thus increasing the comfort level with family planning. However, based on our recent findings, approximately $25 \%$ of patients with MS are exposed to a DMD at any time during the year prior to pregnancy. ${ }^{38}$ Therefore, the increase in pregnancy rates among patients with MS may suggest that clinicians are becoming more comfortable managing the complex reciprocal effects of MS and pregnancy and that significant efforts on the part of the MS neurology community to educate the public and general neurologists are allowing more women with MS to experience motherhood. These analyses of claims data of women with MS and pregnancy showed high rates of several comorbidities and complications, similar to those seen in women without MS. Despite the noted limitations, claims data reflect real-world use patterns and can improve knowledge of the interactions patients with MS have with the health care system, and are a valuable resource for initial exploratory analyses of a variety of health services research questions. More real-world evidence to inform decision-making in women with MS of childbearing age is needed.

\section{Author contributions}

All authors contributed to the study concept and design; acquisition, analysis, or interpretation of data; drafting manuscript or revising it critically; and the approval of the version for submission.

\section{Acknowledgment}

The authors thank Michele Springer (Caudex, New York, $\mathrm{NY}$ ) for assistance with editing and revising the manuscript for nonintellectual content.

\section{Study funding}

Study funded by EMD Serono, Inc., Rockland, MA (a business of Merck KGaA, Darmstadt, Germany). The authors received no funding for their authorship responsibilities in the development of this manuscript.

\section{Disclosure}

M. Houtchens: funding support from EMD Serono, Inc. (a business of Merck KGaA, Darmstadt, Germany); support for service on scientific advisory boards from Biogen, Genzyme Sanofi, Teva Neuroscience, and Novartis; and received research support from Genzyme Sanofi. N. Edwards: employee of Health Services Consulting Corporation. Health Services Consulting Corporation received funding from EMD Serono, Inc. (a business of Merck KGaA, Darmstadt, Germany) to run the analysis. G. Schneider is a former employee of Boston Health Economics, Inc. (BHE). BHE received consulting fees from EMD Serono, Inc. (a business of Merck KGaA, Darmstadt, Germany). K. Stern is a current employee of Boston Health Economics, Inc. (BHE). BHE received consulting fees from EMD Serono, Inc. (a business of Merck KGaA, Darmstadt, Germany). A. Phillips: 
employee of EMD Serono, Inc., Rockland, MA (a business of Merck KGaA, Darmstadt, Germany). Go to Neurology.org/ $\mathrm{N}$ for full disclosures.

\section{Publication history}

Received by Neurology December 15, 2017. Accepted in final form July 23, 2018.

\section{References}

1. National Multiple Sclerosis Society. Who gets MS? Available at: nationalmssociety. org/What-is-MS/Who-Gets-MS. Accessed May 17, 2018.

2. Compston A, Coles A. Multiple sclerosis. Lancet 2008;372:1502-1517.

3. National Multiple Sclerosis Society. Pregnancy and reproductive issues. Available at: nationalmssociety.org/Living-Well-With-MS/Diet-Exercise-Healthy-Behaviors/Womens-Health/Pregnancy. Accessed December 7, 2017.

4. Bove R, Alwan S, Friedman JM, et al. Management of multiple sclerosis during pregnancy and the reproductive years: a systematic review. Obstet Gynecol 2014;124:1157-1168.

5. Dreyer NA, Schneeweiss S, McNeil BJ, et al. GRACE principles: recognizing highquality observational studies of comparative effectiveness. Am J Manag Care 2010;16: $467-471$.

6. Wundes A, Pebdani RN, Amtmann D. What do healthcare providers advise women with multiple sclerosis regarding pregnancy? Mult Scler Int 2014;2014:819216.

7. Rae-Grant A, Day GS, Marrie RA, et al. Practice guideline recommendations summary: disease-modifying therapies for adults with multiple sclerosis: report of the Guideline Development, Dissemination, and Implementation Subcommittee of the American Academy of Neurology. Neurology 2018;90:777-788.

8. Dahl J, Myhr KM, Daltveit AK, Hoff JM, Gilhus NE. Pregnancy, delivery, and birth outcome in women with multiple sclerosis. Neurology 2005;65:1961-1963.

9. Dahl J, Myhr KM, Daltveit AK, Gilhus NE. Planned vaginal births in women with multiple sclerosis: delivery and birth outcome. Acta Neurol Scand Suppl 2006;183:51-54.

10. Dahl J, Myhr KM, Daltveit AK, Gilhus NE. Pregnancy, delivery and birth outcome in different stages of maternal multiple sclerosis. J Neurol 2008;255:623-627.

11. Hellwig K, Brune N, Haghikia A, et al. Reproductive counselling, treatment and course of pregnancy in 73 German MS patients. Acta Neurol Scand 2008;118:24-28.

12. Jalkanen A, Alanen A, Airas L. Pregnancy outcome in women with multiple sclerosis: results from a prospective nationwide study in Finland. Mult Scler 2010;16: 950-955.

13. Knox CA, Delaney JA, Winterstein AG. Anti-diabetic drug utilization of pregnant diabetic women in US managed care. BMC Pregnancy Childbirth 2014;14:28.

14. Lu E, Zhao Y, Dahlgren L, et al. Obstetrical epidural and spinal anesthesia in multiple sclerosis. J Neurol 2013;260:2620-2628.

15. Lu E, Zhu F, van der KM, et al. Labor induction and augmentation in women with multiple sclerosis. Mult Scler 2013;19:1182-1189.

16. Lu E, Zhao Y, Zhu F, et al. Birth hospitalization in mothers with multiple sclerosis and their newborns. Neurology 2013;80:447-452.

17. Marrie RA, Cohen J, Stuve O, et al. A systematic review of the incidence and prevalence of comorbidity in multiple sclerosis: overview. Mult Scler 2015;21:263-281.

18. Runmarker B, Andersen O. Pregnancy is associated with a lower risk of onset and a better prognosis in multiple sclerosis. Brain 1995;118(pt 1):253-261.

19. van der Kop ML, Pearce MS, Dahlgren L, et al. Neonatal and delivery outcomes in women with multiple sclerosis. Ann Neurol 2011;70:41-50.
20. Weinshenker BG, Hader W, Carriere W, Baskerville J, Ebers GC. The influence of pregnancy on disability from multiple sclerosis: a population-based study in Middlesex County, Ontario. Neurology 1989;39:1438-1440.

21. Mueller B, Zhang J, Critchlow C. Birth outcomes and need for hospitalization after delivery among women with multiple sclerosis. Am J Obstet Gynecol 2002;186: $446-452$.

22. Kelly VM, Nelson LM, Chakravarty EF. Obstetric outcomes in women with multiple sclerosis and epilepsy. Neurology 2009;73:1831-1836.

23. Fong A, Chau CT, Quant C, Duffy J, Pan D, Ogunyemi DA. Multiple sclerosis in pregnancy: prevalence, sociodemographic features, and obstetrical outcomes. J Matern Fetal Neonatal Med 2018;31:382-387.

24. Schneeweiss S, Gagne JJ, Glynn RJ, Ruhl M, Rassen JA. Assessing the comparative effectiveness of newly marketed medications: methodological challenges and implications for drug development. Clin Pharmacol Ther 2011;90:777-790.

25. Wyszynski DF, Carman WJ, Cantor AB, et al. Pregnancy and birth outcomes among women with idiopathic thrombocytopenic purpura. J Pregnancy 2016;2016:8297407.

26. Centers for Disease Control and Prevention (CDC). Trends and variations in reproduction and intrinsic rates: United States, 1990-2014. Available at: cdc.gov/nchs/ data/nvsr/nvsr66/nvsr66 02.pdf. Accessed December 12, 2017.

27. Alwan S, Yee IM, Dybalski M, et al. Reproductive decision making after the diagnosis of multiple sclerosis (MS). Mult Scler 2013;19:351-358.

28. Borisow N, Doring A, Pfueller CF, Paul F, Dorr J, Hellwig K. Expert recommendations to personalization of medical approaches in treatment of multiple sclerosis: an overview of family planning and pregnancy. EPMA J 2012;3:9.

29. Prunty MC, Sharpe L, Butow P, Fulcher G. The motherhood choice: a decision aid for women with multiple sclerosis. Patient Educ Couns 2008;71:108-115.

30. Giesser B, Benedetto-Anzai MT. Talking with your MS patients about difficult topics: talking about reproductive issues. Available at nationalmssociety.org/National MSSociety/media/MSNationalFiles/Brochures/Clinical-Bulletin-Reproductive-2010.pdf. Accessed May 3, 2018.

31. Cil AP, Leventoglu A, Sonmezer M, Soylukoc R, Oktay K. Assessment of ovarian reserve and Doppler characteristics in patients with multiple sclerosis using immunomodulating drugs. J Turk Ger Gynecol Assoc 2009;10:213-219.

32. Thone J, Kollar S, Nousome D, et al. Serum anti-Müllerian hormone levels in reproductive-age women with relapsing-remitting multiple sclerosis. Mult Scler 2015; 21:41-47.

33. Centers for Disease Control and Prevention (CDC). Update on overall prevalence of major birth defects-Atlanta, Georgia, 1978-2005. MMWR Morb Mortal Wkly Rep 2008;57:1-5.

34. Cadarette SM, Wong L. An introduction to health care administrative data. Can J Hosp Pharm 2015;68:232-237.

35. Schneeweiss S, Avorn J. A review of uses of health care utilization databases for epidemiologic research on therapeutics. J Clin Epidemiol 2005;58:323-337.

36. Alwan S, Chambers CD, Armenti VT, Sadovnick AD. The need for a disease-specific prospective pregnancy registry for multiple sclerosis (MS). Mult Scler Relat Disord 2015;4:6-17.

37. Mahlanza TD, Sadovnick D, Houtchens MK. PREG-MS: the New England multiple sclerosis pregnancy prospective cohort study. Presented at the 32nd Congress of the European Committee for Treatment and Research in Multiple Sclerosis (ECTRIMS); September 14-17, 2016; London; Abstract P863.

38. Houtchens MK, Edwards NC, Phillips AL. Disease-modifying drug treatment before, during, and after pregnancy in women with multiple sclerosis and a live birth. Presented at the 31st annual Meeting of the Consortium of Multiple Sclerosis Centers (CMSC); May 24-27, 2017; New Orleans; Poster DX11. 


\section{Neurology}

Pregnancy rates and outcomes in women with and without MS in the United States

Maria K. Houtchens, Natalie C. Edwards, Gary Schneider, et al.

Neurology 2018;91;e1559-e1569 Published Online before print September 28, 2018

DOI 10.1212/WNL.0000000000006384

This information is current as of September 28, 2018

\begin{tabular}{|c|c|}
\hline $\begin{array}{l}\text { Updated Information \& } \\
\text { Services }\end{array}$ & $\begin{array}{l}\text { including high resolution figures, can be found at: } \\
\text { http://n.neurology.org/content/91/17/e1559.full }\end{array}$ \\
\hline References & $\begin{array}{l}\text { This article cites } 32 \text { articles, } 5 \text { of which you can access for free at: } \\
\text { http://n.neurology.org/content/91/17/e1559.full\#ref-list-1 }\end{array}$ \\
\hline Citations & $\begin{array}{l}\text { This article has been cited by } 1 \text { HighWire-hosted articles: } \\
\text { http://n.neurology.org/content/91/17/e1559.full\#\#otherarticles }\end{array}$ \\
\hline Subspecialty Collections & $\begin{array}{l}\text { This article, along with others on similar topics, appears in the } \\
\text { following collection(s): } \\
\text { Multiple sclerosis } \\
\text { http://n.neurology.org/cgi/collection/multiple_sclerosis }\end{array}$ \\
\hline Permissions \& Licensing & $\begin{array}{l}\text { Information about reproducing this article in parts (figures,tables) or in } \\
\text { its entirety can be found online at: } \\
\text { http://www.neurology.org/about/about_the_journal\#permissions }\end{array}$ \\
\hline Reprints & $\begin{array}{l}\text { Information about ordering reprints can be found online: } \\
\text { http://n.neurology.org/subscribers/advertise }\end{array}$ \\
\hline
\end{tabular}

Neurology $\mathbb{B}$ is the official journal of the American Academy of Neurology. Published continuously since 1951, it is now a weekly with 48 issues per year. Copyright Copyright ( $\odot 2018$ The Author(s). Published by Wolters Kluwer Health, Inc. on behalf of the American Academy of Neurology.. All rights reserved. Print ISSN: 0028-3878. Online ISSN: 1526-632X.

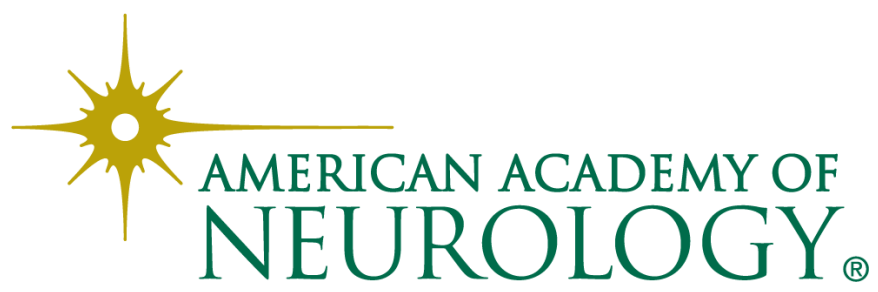

